\title{
Proteoglycans of the Intervertebral Disc
}

\author{
ABSENCE OF DEGRADATION DURING THE ISOLATION OF PROTEOGLYCANS \\ FROM THE INTERVERTEBRAL DISC
}

\author{
By RICHARD L. STEVENS, PHILIP G. DONDI and HELEN MUIR \\ Division of Biochemistry, Kennedy Institute of Rheumatology, Bute Gardens, London W6 7 DW, U.K.
}

(Received 21 August 1978)

\begin{abstract}
Proteoglycans extracted with $4 \mathrm{M}$-guanidinium chloride from pig intervertebral discs, and purified by equilibrium density-gradient centrifugation in $\mathrm{CsCl}$, were of smaller hydrodynamic size than those extracted and purified in the same way from the laryngeal cartilage of the same animal. Whether this difference in size arose from degradation during the extraction and purification of the proteoglycans of the disc was investigated. Purified proteoglycans labelled either in the chondroitin sulphate chains or in the core protein were obtained from laryngeal cartilage by short-term organ culture. These labelled proteoglycans were added at the beginning of the extraction of the disc proteoglycans, and labelled cartilage and unlabelled disc proteoglycans were isolated and purified together. There was no appreciable loss of radioactivity after density-gradient centrifugation nor decrease in hydrodynamic size of the labelled cartilage proteoglycans on chromatography on Sepharose 2B, when these were present during the extraction of disc proteoglycans. It is concluded that disc proteoglycans are intrinsically of smaller size than cartilage proteoglycans and this difference in size does not arise from degradation during the extraction.
\end{abstract}

Proteoglycans isolated from pig and human intervertebral discs, as described in the preceding paper (Stevens et al., 1979), were found to be of smaller size than the proteoglycans of pig laryngeal cartilage, when assessed by gel chromatography and analytical ultracentrifugation.

Nevertheless, the proteoglycans of pig intervertebral discs are able to bind to hyaluronic acid and contain a keratan sulphate-rich region and a chondroitin sulphate region (Stevens et al., 1979), as do proteoglycans from pig laryngeal cartilage. However, the lower relative proportions of uronic acid and galactosamine in disc proteoglycans suggests that the chondroitin sulphate region in these macromolecules is smaller than in cartilage proteoglycans, either in length of the chondroitin sulphate chains or in the length of the core protein, and hence in the number of chains in the molecule. This could have arisen from the action of degradative enzymes during the isolation procedure, because disc and hyaline cartilage proteoglycans appear otherwise to be similar in many ways. Proteolytic enzymes which degrade proteoglycans to smaller size have been shown in the Swarm rat chondrosarcoma (Oegema et al., 1975) and in human intervertebral discs (Pearson et al., 1974). Sapolsky et al. (1976) have reported on metalloproteinases in human articular

Abbreviation used: SDS, sodium dodecyl sulphate. cartilage capable of digesting articular-cartilage proteoglycans to fragments with five to twelve chondroitin sulphate chains, and Roughley \& Barrett (1977) have investigated the degradation of proteoglycans of nasal cartilage by six proteinases, including cathepsins B, D and G, and lysosomal elastase. Pearson \& Mason (1977) have also studied in considerable detail the stability of cartilage proteoglycans and the importance of adding inhibitors of proteolytic enzymes during their isolation and storage.

To ensure that degradation was avoided, all specimens were kept frozen before analysis, and the extraction was carried out at $4^{\circ} \mathrm{C}$. High concentrations of inhibitors of proteolytic enzymes (Oegema et al., 1975) were present throughout the extraction, dialysis and associative density-gradient centrifugation and the $\mathrm{pH}$ was not allowed to fall below 5.8, where lysosomal enzymes such as cathepsin D (Bjelle \& Osterlin, 1976; Sapolsky et al., 1974) are most active. Moreover, certain lysosomal enzymes such as glucuronidase are inactive in $4 \mathrm{M}$-guanidinium chloride (R. L. Stevens, unpublished work) and 'free' chondroitin sulphate chains were not detected during the isolation procedure. This suggested that the smaller size of disc proteoglycans was intrinsic to these molecules. Whether degradation of exogenous labelled proteoglycans took place during the extraction of disc proteoglycans has been examined here. 


\section{Materials}

All reagents were as described in the preceding paper (Stevens et al., 1979), and in addition Eagle's Basal Medium was from Gibco Bio-Cult (Paisley, Scotland, U.K.), and L-[G- $\left.{ }^{3} \mathrm{H}\right]$ leucine and $\mathrm{D}-\left[6-{ }^{3} \mathrm{H}\right]-$ glucosamine were from The Radiochemical Centre (Amersham, Bucks., U.K.). Alcian Blue and Coomassie Brilliant Blue were obtained respectively from Hopkin and Williams (Chadwell Heath, Essex, U.K.) and BDH Chemicals (Poole, Dorset, U.K.).

\section{Methods}

\section{Analytical methods}

Uronic acid was measured as described in the preceding paper (Stevens et al., 1979). Radioactivity (d.p.m.) was measured in a Searle mark III liquidscintillation spectrometer. Samples $(3 \mathrm{ml})$ were placed in $5 \mathrm{ml}$ of Luma Gel scintillation fluid (Lumac Systems, Basel, Switzerland) and a correction for background corresponding to the buffer alone was subtracted from the observed radioactivity counts of each sample.

The presence of protein contaminants such as link protein in proteoglycan fractions was investigated by SDS/polyacrylamide-gel electrophoresis (Fairbanks et al., 1971). A running gel of $7.5 \%(\mathrm{w} / \mathrm{v})$ polyacrylamide and a stacking gel of $4 \%(\mathrm{w} / \mathrm{v})$ polyacrylamide were employed. Samples were dissolved in $0.01 \mathrm{M}$ Tris $/ \mathrm{HCl}, \mathrm{pH} 8.0$, containing $0.001 \mathrm{M}-\mathrm{EDTA}, 0.1 \%$ $(w / v)$ SDS and $10 \%(w / v)$ sucrose, at a concentration of $2 \mathrm{mg}$ dry wt./0.1 ml. Electrophoresis was carried out in $0.2 \mathrm{M}$-sodium acetate/0.04 $\mathrm{M}$-Tris/HCl, $\mathrm{pH} 7.4$, containing $0.1 \%(\mathrm{w} / \mathrm{v})$ SDS and $0.002 \mathrm{M}$-EDTA at a constant current of $2.5 \mathrm{~mA} /$ tube. Gels were stained with either $0.05 \%(\mathrm{w} / \mathrm{v})$ Coomassie Brilliant Blue in $25 \%(\mathrm{v} / \mathrm{v})$ propan-2-ol and $10 \%(\mathrm{v} / \mathrm{v})$ acetic acid or $0.5 \%(\mathrm{w} / \mathrm{v})$ Alcian Blue in 3\% (v/v) acetic acid. Gels were destained in $10 \%$ propan-2-ol containing $10 \%$ acetic acid.

\section{Incubation in vitro}

Laryngeal cartilage of a single pig was prepared and cut into small pieces and incubated in supplemented Eagle's Basal Medium as previously described (Dondi \& Muir, 1976), except that approx. $5.0 \mathrm{~g}$ wet wt. of tissue was placed in a sterile screw-top $100 \mathrm{ml}$ jar (Richardson's of Leicester Ltd., Leicester, U.K.).

The tissue was incubated at $37^{\circ} \mathrm{C}$ for $30 \mathrm{~min}$ in a Gallenkamp shaking water bath before $\mathrm{D}-\left[6{ }^{3} \mathrm{H}\right]$ glucosamine hydrochloride or $\mathrm{L}-\left[\mathrm{G}-{ }^{3} \mathrm{H}\right]$ leucine was added to the medium $(50 \mu \mathrm{Ci} / \mathrm{ml})$. After $4 \mathrm{~h}$ the incubation was stopped by cooling in ice, removing the medium and washing the tissue with ice-cold water.

\section{Preparative methods}

Cartilage proteoglycans. Labelled proteoglycans were extracted from cartilage in the same way as from intervertebral disc, as described in the preceding paper (Stevens et al., 1979). The suspension was filtered through glass wool and the retained cartilage washed with a small volume of fresh extracting solution. Extract and washings were combined and dialysed for 2 days against $7 \mathrm{vol}$. of $0.05 \mathrm{M}$-sodium acetate containing the same four proteinase inhibitors at the same concentrations as above. To the dialysis residue, which now contained $0.5 \mathrm{M}$-guanidinium chloride, solid $\mathrm{CsCl}$ was added and the proteoglycans were purified by associative and dissociative equilibrium density-gradient centrifugation as described in the preceding paper (Stevens et al., 1979), except that higher starting densities of $1.6 \mathrm{~g} / \mathrm{ml}$ and $1.5 \mathrm{~g} / \mathrm{ml}$ respectively were used. After dialysis the bottom fraction from the second centrifugation (A1-D1) was divided into several portions for analysis and for assessment of hydrodynamic size by gel chromatography on Sepharose 2B.

Extraction of disc proteoglycans in the presence of labelled cartilage proteoglycans. Four nuclei pulposi were pooled, extracted and purified by associative and dissociative density-gradient centrifugation as described in the preceding paper (Stevens et al., 1979), except that pig laryngeal-cartilage proteoglycan labelled with $\left[{ }^{3} \mathrm{H}\right]$ glucosamine $(1.8 \mathrm{mg}$ of uronic acid, approx. $7.2 \mathrm{mg}$ of proteoglycan) or with $\left[{ }^{3} \mathrm{H}\right]$ leucine $(10 \mathrm{mg}$ of uronic acid, approx. $40 \mathrm{mg}$ of proteoglycan) was added to the extracting solution $(14 \mathrm{ml}$ volume). The radioactivity (d.p.m.) was measured after dialysis of the extract to associative conditions and in all fractions from the density gradients. Efficiency of extraction from nucleus pulposus is high ( $>90 \%$; Stevens et al., 1979) in the absence of added proteoglycan, but was not measured in this instance.

\section{Gel chromatography}

Sephadex G-200 chromatography of glycosaminoglycans. Free chondroitin sulphate chains were obtained from cartilage proteoglycans labelled with $\left[{ }^{3} \mathrm{H}\right]$ glucosamine by treatment with alkali and $\mathrm{NaB}^{3} \mathrm{H}_{4}$ as described in the preceding paper (Stevens et al., 1979). After neutralization the solution was divided in approximately half. One half was applied directly to a Sephadex G-200 column $(140 \mathrm{~cm} \times 1.0 \mathrm{~cm})$ and eluted with $0.2 \mathrm{M}-\mathrm{NaCl} / 0.05 \mathrm{M}-\mathrm{Tris} / \mathrm{HCl}, \mathrm{pH} 7.0$, at a flow rate of $4 \mathrm{ml} / \mathrm{h}$. The other half was exhaustively dialysed against water, freeze-dried, redissolved in $0.5 \mathrm{ml}$ of $0.05 \mathrm{M}$-sodium acetate $/ 0.05 \mathrm{M}$-Tris $/ \mathrm{HCl}$, $\mathrm{pH} 8.0$, with $0.01 \%(\mathrm{w} / \mathrm{v})$ bovine serum albumin, digested with 1 unit of chondroitinase $A B C$ for $1 \mathrm{~h}$ at $37^{\circ} \mathrm{C}$ by the method of Saito et al. (1968), and applied to the same Sephadex G-200 solumn. Fractions 
$(1.5 \mathrm{ml})$ were collected and analysed for radioactivity and uronic acid content.

Proteoglycans obtained from dissociative densitygradient centrifugation

Molecular size assessed by gel chromatography. Samples of proteoglycans obtained from the bottom fraction of the dissociative density-gradient centrifugation (A1-D1) were dissolved in $4.0 \mathrm{M}$-guanidinium chloride $/ 0.05 \mathrm{M}$-sodium acetate, $\mathrm{pH} 5.8$, at a concentration of $1.0-1.5 \mathrm{mg}$ of uronic acid $/ \mathrm{ml}$, and $1 \mathrm{ml}$ of the solution was applied to a column $(165 \mathrm{~cm} \times$ $1.4 \mathrm{~cm}$ ) of Sepharose 2B. The column was eluted at $4^{\circ} \mathrm{C}$ with the same buffer at $2 \mathrm{ml} / \mathrm{h}$. Each fraction $(2.4 \mathrm{ml})$ was analysed for radioactivity and after exhaustive dialysis against water for uronic acid content.

Interaction with hyaluronic acid. Proteoglycan solutions were also prepared in $0.5 \mathrm{M}$-sodium acetate, pH5.8, at concentrations of $1-1.5 \mathrm{mg}$ of uronic acid $/ \mathrm{ml}$ and samples $(1 \mathrm{ml})$ mixed with $15 \mu \mathrm{l}$ of a solution of hyaluronic acid in the same buffer containing $2 \mathrm{mg}$ of hyaluronic acid $/ \mathrm{ml}$. The mixed solution was applied to a column $(160 \mathrm{~cm} \times 1.6 \mathrm{~cm})$ of Sepharose $2 \mathrm{~B}$, which was eluted at $4^{\circ} \mathrm{C}$ with the same buffer at a rate of $7 \mathrm{ml} / \mathrm{h}$ by using a peristaltic pump (Watson Marlow, Falmouth, Cornwall, U.K.). Fractions $(4 \mathrm{ml})$ were collected and their radioactivity and uronic acid contents determined.

\section{Results}

Isolation and characterization of radioactively labelled laryngeal-cartilage proteoglycans

After dissociative density-gradient centrifugation, $18 \mathrm{mg}$ of uronic acid of laryngeal-cartilage proteoglycan was obtained from each preparation. The relative specific radioactivity was 110000 d.p.m./mg of uronic acid when $\left[{ }^{3} \mathrm{H}\right]$ glucosamine was the precursor and 13900 d.p.m./mg of uronic acid when $\left[{ }^{3} \mathrm{H}\right]$ leucine was the precursor.

As judged by SDS/polyacrylamide-gel electrophoresis (Fig. 1), the proteoglycan preparations were free from contaminating glycoproteins, which would also have been labelled. No protein of lower molecular weight that should have migrated into the running gel was detected, and all protein that also stained with Alcian Blue remained in the top stacking gel.

When proteoglycans labelled with $\left[{ }^{3} \mathrm{H}\right]$ glucosamine as the precursor were subjected to alkaline $\beta$-elimination, the ${ }^{3} \mathrm{H}$ was found mainly in chondroitin sulphate chains, since, firstly, on chromatography on Sephadex G-200, the majority of the radioactivity was eluted in the same position as the chondroitin sulphate chains assayed as uronic acid (Fig. 2a), and, secondly, after digestion with chondroitinase ABC, the majority of the radioactivity was eluted with the

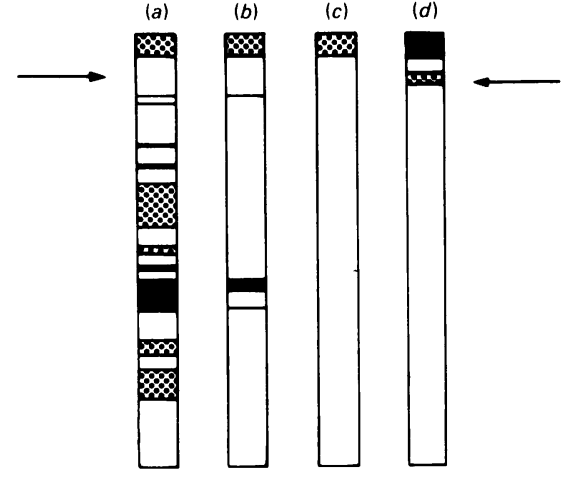

Fig. 1. SDS/polyacrylamide-gel electrophoresis of ${ }^{3} \mathrm{H}$ labelled laryngeal proteoglycans at different stages of purification

Gels: (a), 4M-guanidinium chloride extract; (b), fraction Al after associative equilibrium densitygradient centrifugation; $(c)$ and $(d)$, fraction A1-D1 after dissociative equilibrium density-gradient centrifugation of fraction A1. Gels $(a),(b)$ and $(c)$ were stained with Coomassie Brilliant Blue, and gel $(d)$ with Alcian Blue. Arrows mark the junction of the running gel and the stacking gel.

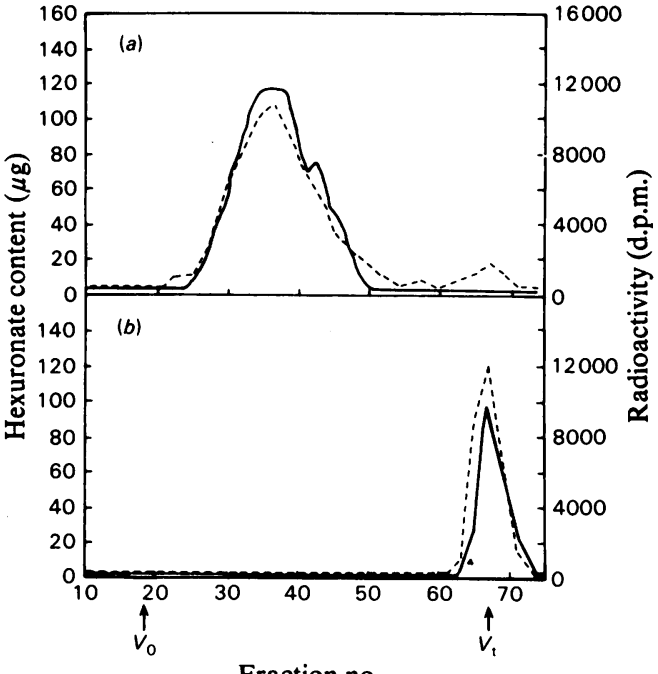

Fraction no.

Fig. 2. Gel chromatography on Sephadex $\mathrm{G}-200$ of $\left[{ }^{3} \mathrm{H}\right] \mathrm{glu}$ cosamine-labelled cartilage proteoglycans

Proteoglycans were treated with $(a) 0.5 \mathrm{M}-\mathrm{NaOH}$ and (b) chondroitinase ABC. The total uronic acid (-) content and radioactivity (---) of each fraction were determined. $V_{0}$ and $V_{t}$ mark the void volume and the total volume of the column respectively.

uronic acid in the position of chondroitin sulphate disaccharides (Fig. 2b). 


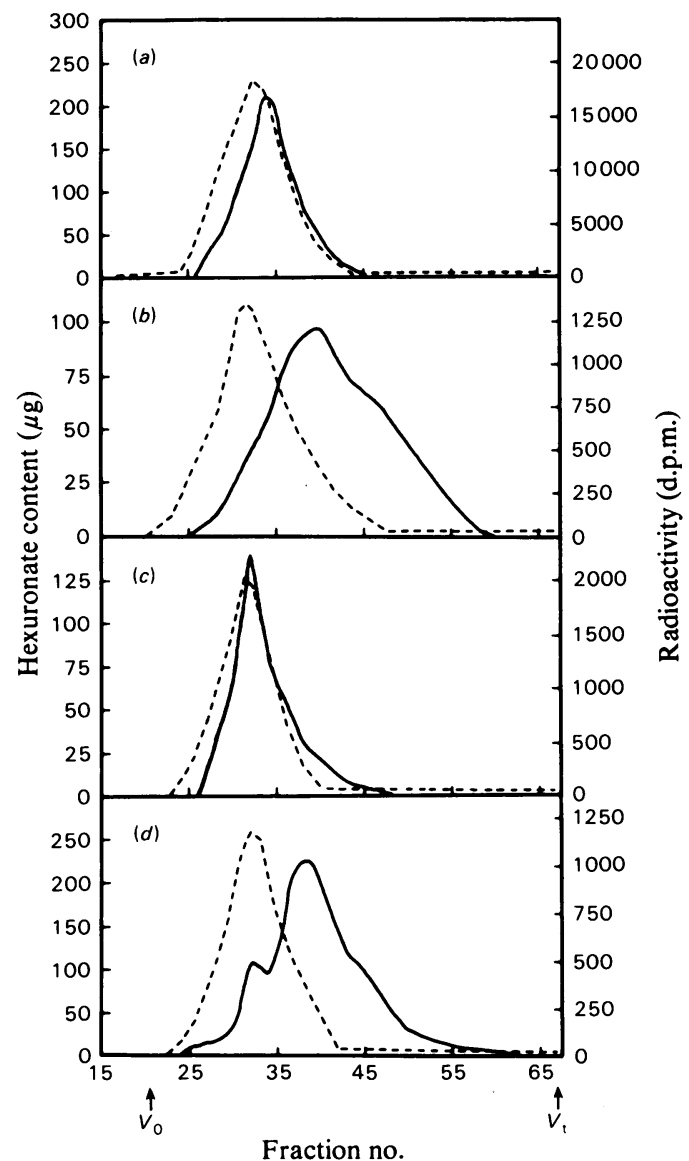

Fig. 3. Gel chromatography on Sepharose $2 B$ of dissociated monomeric proteoglycans

(a) $\left.{ }^{3} \mathrm{H}\right] \mathrm{Glucosamine-labelled} \mathrm{laryngeal-cartilage}$ proteoglycans; $(b)$ after co-extraction with excess disc proteoglycans. (c) $\left[{ }^{3} \mathrm{H}\right]$ Leucine-labelled laryngeal-cartilage proteoglycans; $(d)$ after co-extraction with excess disc proteoglycans. The total uronic acid (-) content and radioactivity (---) of each fraction were determined. $V_{0}$ and $V_{\mathrm{t}}$ mark the void volume and the total volume of the column respectively.

Effect of the extraction procedure on ${ }^{3} \mathrm{H}$-labelled laryngeal-cartilage proteoglycans

Size. Proteoglycans synthesized by short-term organ culture of cartilage with either $\left[{ }^{3} \mathrm{H}\right]$ glucosamine (Fig. $3 a$ ) or $\left[{ }^{3} \mathrm{H}\right]$ leucine (Fig. $3 c$ ) as precursors were eluted in the same position irrespective of the precursor used and were of large molecular size, similar to those pre-existing in the cartilage as judged by chromatography on Sepharose 2B (Figs. $3 a$ and $3 b$ ). The elution profile of radioactivity, however, did not
Table 1. Recovery after associative and dissociative equilibrium density-gradient centrifugation of proteoglycans labelled with either $\left[{ }^{3} \mathrm{H}\right]$ glucosamine or $\left[{ }^{3} \mathrm{H}\right]$ leucine For details see the text.

\begin{tabular}{|c|c|c|}
\hline & \multicolumn{2}{|c|}{ Radioactivity } \\
\hline & \multicolumn{2}{|c|}{ (d.p.m.) $(\%$ of tota } \\
\hline $\begin{array}{l}\text { H]Glucosamine-labelled } \\
\text { proteoglycans }\end{array}$ & & \\
\hline Associative: A2 (top $\frac{3}{4}$ ) & 4200 & 5.9 \\
\hline Dissociative: A1-D1 (bottom $\frac{1}{4}$ ) & 137500 & 96.6 \\
\hline $\begin{array}{l}\left.\text { A1-D2 (top } \frac{3}{4}\right) \\
{\left[{ }^{3} \mathrm{H}\right] \text { Leucine-labelled }} \\
\text { proteoglycans }\end{array}$ & 600 & 0.4 \\
\hline Associative: A2 (top $\left.\frac{3}{4}\right)$ & 6200 & 5.9 \\
\hline Dissociative: A1-D1 (bottom $\frac{1}{4}$ ) & 97500 & 93.0 \\
\hline A1-D2 (top $\left.\frac{3}{4}\right)$ & 1100 & 1.1 \\
\hline
\end{tabular}

coincide completely with the elution profile of uronic acid and suggested that these newly formed molecules were, if anything, of slightly larger size and therefore distinct from those in the disc.

When cartilage proteoglycans labelled with $\left[{ }^{3} \mathrm{H}\right]$ glucosamine or $\left[{ }^{3} \mathrm{H}\right]$ leucine were present throughout the extraction of unlabelled disc proteoglycans with $4 \mathrm{M}$-guanidinium chloride, 99.7 and $99.3 \%$ respectively of the total radioactivity was recovered in the nondiffusible material after dialysis to a concentration of $0.5 \mathrm{M}$-guanidinium chloride. The extracts were centrifuged under associative conditions and the radioactivity of each fraction was determined. The bottom fraction (A1) was then centrifuged under dissociative conditions and the radioactivity determined in the lower and upper fractions. The bottom fractions (A1-D1), which contained the majority of proteoglycans (Table 1), contained almost all the radioactivity. Thus there was no appreciable degradation of the glycosaminoglycans or of the protein core to fragments small enough either to be lost on dialysis or to appear in fractions of lower density.

When the mixture of proteoglycan from discs and cartilage was chromatographed on Sepharose 2B a considerable difference in hydrodynamic size was seen (Fig. 3). Because the disc proteoglycans were in 10-fold excess over the glucosamine-labelled cartilage proteoglycans, the uronic acid elution profile mainly represents the disc proteoglycans, whereas the radioactivity profile represents cartilage proteoglycans which were eluted earlier than disc proteoglycans (Fig. 3b). The position of elution was the same whether the glycosaminoglycans or protein core were labelled. It is notable that there was no change in elution and hence in hydrodynamic size of leucinelabelled cartilage proteoglycans when these had been present throughout the extraction of disc proteoglycans (Figs. $3 b, 3 d$ ). 


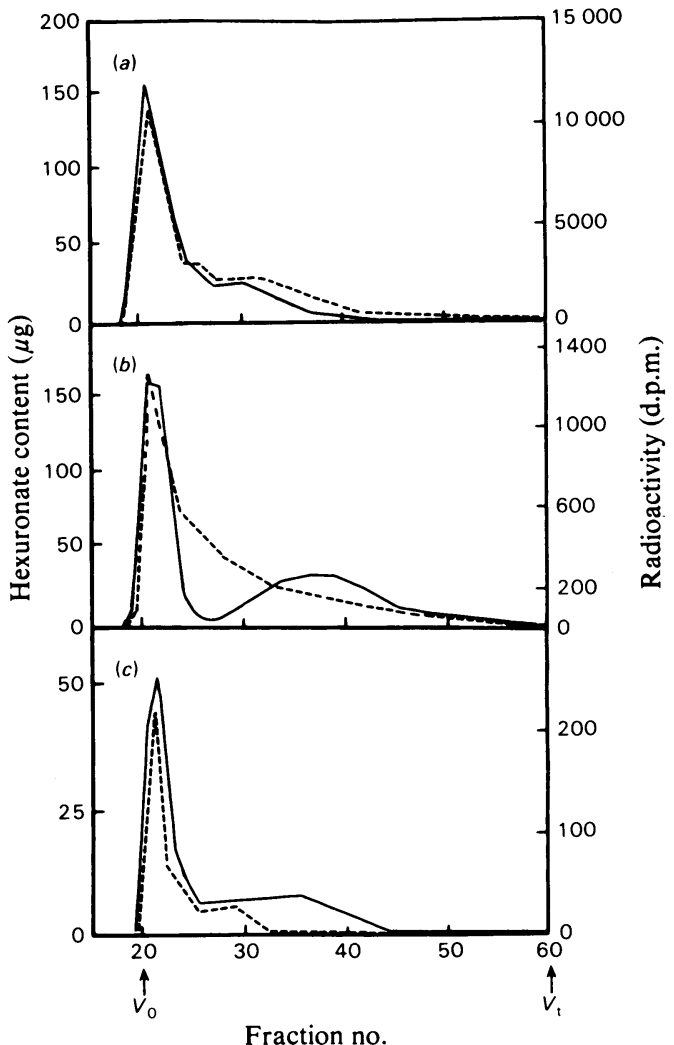

Fig. 4. Gel chromatography on Sepharose $2 B$ of dissociated monomeric proteoglycan in the presence of $1 \%(w / w)$ hyaluronic acid

(a) $\left[{ }^{3} \mathrm{H}\right] \mathrm{Glucosamine-labelled} \mathrm{laryngeal} \mathrm{proteogly-}$ cans alone; $(b)$ after co-extraction with excess disc proteoglycans; (c) $\left[{ }^{3} \mathrm{H}\right]$ leucine-labelled laryngeal proteoglycans after co-extraction with excess disc proteoglycans. The total uronic acid content (-) and radioactivity (---) of each fraction was determined. $V_{0}$ and $V_{t}$ mark the void volume and the total volume of the column respectively.

Interaction with hyaluronic acid. In the presence of hyaluronic acid under non-dissociating conditions, the majority of (monomeric) proteoglycans of cartilage became excluded from Sepharose 2B (Fig. $4 a$ ), and, since the radioactivity was co-eluted with the uronic acid, newly formed proteoglycans were also able to interact with hyaluronate. This ability was essentially unaffected when the cartilage proteoglycans were co-extracted with disc proteoglycans (Fig. 4b), despite the effects of four density-gradient centrifugation runs and the consequent extensive handling. Similar results were obtained with $\left[{ }^{3} \mathrm{H}\right]$ leucine-labelled cartilage proteoglycans (Fig. $4 c$ ).

\section{Discussion}

Proteoglycans of the disc differ from laryngealcartilage proteoglycans principally in being of much smaller hydrodynamic size and in containing less chondroitin sulphate. Proteoglycans of various non-cartilaginous tissues have now been reported, such as a heparan sulphate proteoglycan in brain (White \& Hardy, 1977; Margolis et al., 1976), a chondroitin sulphate proteoglycan in aorta (Eisenstein et al., 1975; Radhakrishnamurthy et al., 1977) and a keratan sulphate proteoglycan in cornea (Axelsson \& Heinegård, 1978). The sizes of none of these so far appear to be comparable with those of proteoglycans of hyaline cartilage. However, because of difficulties inherent in extracting proteoglycans from different types of connective tissues, the procedures used are not necessarily the same, nor are the factors that might cause degradation of these macromolecules during their purification. Because the structure of proteoglycans renders them inherently vulnerable to attack by lysosomal and neutral proteinases, stringent controls are necessary to ensure that such degradation is minimized.

The possibility that disc proteoglycans were smaller because they had undergone proteolytic degradation of either the chondroitin sulphate-rich region (Heinegård \& Axelsson, 1977) or the hyaluronatebinding region (Heinegård \& Hascall, 1974) during their preparation appeared unlikely, because labelled cartilage proteoglycans when present throughout the extraction procedure suffered no change in molecular size, and the ability to interact with hyaluronate was retained. Further, there was little evidence of degradation of the carbohydrate chains of the proteoglycans, because no significant amounts of free or labelled chondroitin sulphate chains were detected in other density-gradient fractions. This suggests that in vivo any partially degraded molecules and glycosaminoglycan fragments are normally rapidly removed from the tissue.

Whether proteoglycans, like collagen (Bellamy \& Bornstein, 1971) or elastin (Foster et al., 1976), are first synthesized as larger polypeptides which then undergo specific proteolytic cleavages before deposition in connective tissue is not known. The smaller size of human disc proteoglycans might arise from more extensive cleavage of the chondroitin sulphatebearing region during synthesis. Although the size of newly formed disc proteoglycans was not determined, the amino acid sequences around the regions where glycosaminoglycans are attached (Isemura \& Ikenaka, 1975; Hopwood \& Robinson, 1974) suggest that disc and cartilage proteoglycans are homologous, but not identical. From the present results it would appear that, in vivo, disc proteoglycans are intrinsically of smaller size. 
This work was supported by the Arthritis Foundation of Atlanta, GA, U.S.A., and the Medical Research Council, U.K.

\section{References}

Axelsson, I. \& Heinegård, D. (1978) Biochem. J. 169, $517-530$

Bellamy, G. \& Bornstein, P. (1971) Proc. Natl. Acad. Sci. U.S.A. 68, 1138-1142

Bjelle, A. \& Osterlin, S. (1976) J. Rheumatol. 3, 400-408

Dondi, P. \& Muir, H. (1976) Biochem. J. 160, 117-120

Eisenstein, R., Larsson, S.-E., Kuettner, K. E., Sorgente, N. \& Hascall, V. C. (1975) Atherosclerosis 22, 1-17

Fairbanks, G., Steck, T. L. \& Wallach, D. F. H. (1971) Biochemistry 10, 2606-2617

Foster, J. A., Mecham, R. P. \& Franzblau, C. (1976) Biochem. Biophys. Res. Commun. 72, 1399-1406

Heinegård, D. \& Axelsson, I. (1977) J. Biol. Chem. 252, 1971-1979

Heinegård, D. \& Hascall, V. C. (1974) J. Biol. Chem. 249, 4250-4256

Hopwood, J. J. \& Robinson, H. C. (1974) Biochem. J. 141, 517-526

Isemura, M. \& Ikenaka, T. (1975) Biochim. Biophys. Acta 411, 11-21
Margolis, R. U., Lalley, K., Kiang, W.-L., Crockett, C. \& Margolis, R. K. (1976) Biochem. Biophys. Res. Commun. 73, 1018-1024

Oegema, T. R., Hascall, V. C. \& Dziewiatkowski, D. D. (1975) J. Biol. Chem. 250, 6151-6159

Pearson, C. H., Happey, F., Naylor, A., Osborn, J. M. \& Turner, R. L. (1974) in Connective Tissues (Fricke, R. \& Hartmann, R., eds.), pp. 158-165, Springer-Verlag, Berlin

Pearson, J. P. \& Mason, R. M. (1977) Biochim. Biophys. Acta 498, 176-188

Radhakrishnamurthy, B., Ruiz, H. A., Jr. \& Berenson, G. S. (1977) J. Biol. Chem. 252, 4831-4841

Roughley, P. J. \& Barrett, A. J. (1977) Biochem. J. 167, 629-637

Saito, H., Yamagata, T. \& Suzuki, S. (1968) J. Biol. Chem. 243, 1536-1542

Sapolsky, A. I., Howell, D. S. \& Woessner, J. F., Jr. (1974) J. Clin. Invest. 53, 1044-1053

Sapolsky, A. I., Keiser, H., Howell, D. S. \& Woessner, J. F., Jr. (1976) J. Clin. Invest. 58, 1030-1041

Stevens, R. L., Ewins, R. J. F., Revell, P. A. \& Muir, H. (1979) Biochem. J. 179, 561-572

White, C. J. B. \& Hardy, J. F. (1977) FEBS Lett. 78, 229-232 